\title{
Arte y Antropología
}

\section{LETRAS del SUR}

Jorge Aguilera, (1954 - 1997), poeta collipullano, hijo de padre obrero y madre campesina, fue Director de la Corporación Cultural de Collipulli y dirigió también la Revista de Poesía Eratos.

Los versos seleecionados, aparecidos en el libro Yo Me Nombro, reflejan un auténtico sentido de igualdad y esperanza en un mundo cada vez más desencantado.

\section{Me Nambra}

(Extraçto)

Me nombro:

Soy la VIDA; demostración de vida èterna que no cambia, no termina, no transige, no escapa.

Soy vida empezando, creciendo, cultivándose corriendo pletórica, deteniéndose por instantes

llenando todo de aura inmortal. Yo me nombro

soy el hombre que ha venido desde siempre

a galope tendido, enancado al viento

sin coraza, desnudo y sin miedo a deciros sus verdades y sus sueños

dejando como huella de su aterrizaje

\section{Y Vay Diecenda (Extracto)}

Yo soy el hombre que, nacido en invierno, llegó a este canto jinete del viento con una mochila por vestimenta, la que traía colmada de versos.

Versos que son gritos del alma, llamando a ser como niños aunque peinemos canas o úlceras abiertas vomitando fuego.

(Como el Viento amo todo lo gris y lo abierto...)

Aunque soporto un fardo inmenso, doblando mi espalda como la cruz a Cristo. El que aumenta como pasa el tiempo si en mis esquinas que todo lo quieren encuentro hambres gritando en el niño, el ronco estertor de un pecho herido el olvido o la paloma caídos de olvido, un obrero con su mirada rota o el amor olvidado que denigra al hombre enturbiando un espíritu que naciera limpido. 


\section{GRABADOS}

¡El hombre crece hacia su interior!

¡Esa es la evolución!

Tenemos un deber para con ella. Crezcamos para que los monigotes del placer de la avaricia y la figuración

detenidos por los siglos en su ego

Se terminen iy hágase la historia!

¡Que se muestre la historia de los pueblos!

No la historia de los caudillos

Prohombres del mal

Artífices insensatos e interesados de la violencia.

Terminemos los mausoleos del odio donde se ocultan las osamentas de sus

$$
\text { gestores. }
$$

Y brindemos loas a los héroes de cada día porque son los únicos y los verdaderos.

\section{Grabado 1.}

El desaparecido sueña desde su estado muerte, de viaje. En su sueño tres símbolos aparecen y le dan paz. Un helecho, una cantábrida o ciervo volante y una alfombra de pasto de su región. El helecho corona su cabeza, la cantábrida recuerda sus juegos de infancia de los cuales se sostiene en su tragedia, es el medio que lo ata a lo más bello. La alfombra de pasto es el medio natural donde vivió, donde reposa su cuerpo mientras cuerpo viaja.
Roberto Arroyo, profesor de Artes Plásticas egresado de la Facultad de Artes de la Universidad Austral de Valdivia, oriundo de Gorbea, ha vinculado su quehacer artístico al trabajo de la promoción de los Derechos Humanos, labor que continúa extendiendo hoy en día en los EE. UU.-, y que le ha brindado bastantes méritos sobre todo a nivel internacional, donde se conoce y aprecia su obra.

Presentamos ahora dos muestras de lo que fue su exposición en el Encuentro Juntas Construyamos la Paz, llevado a cabo en Croacia - Porec a fines de septiembre de 1998. Agregamos una interpretación de cada obra hecha por el propio artista.

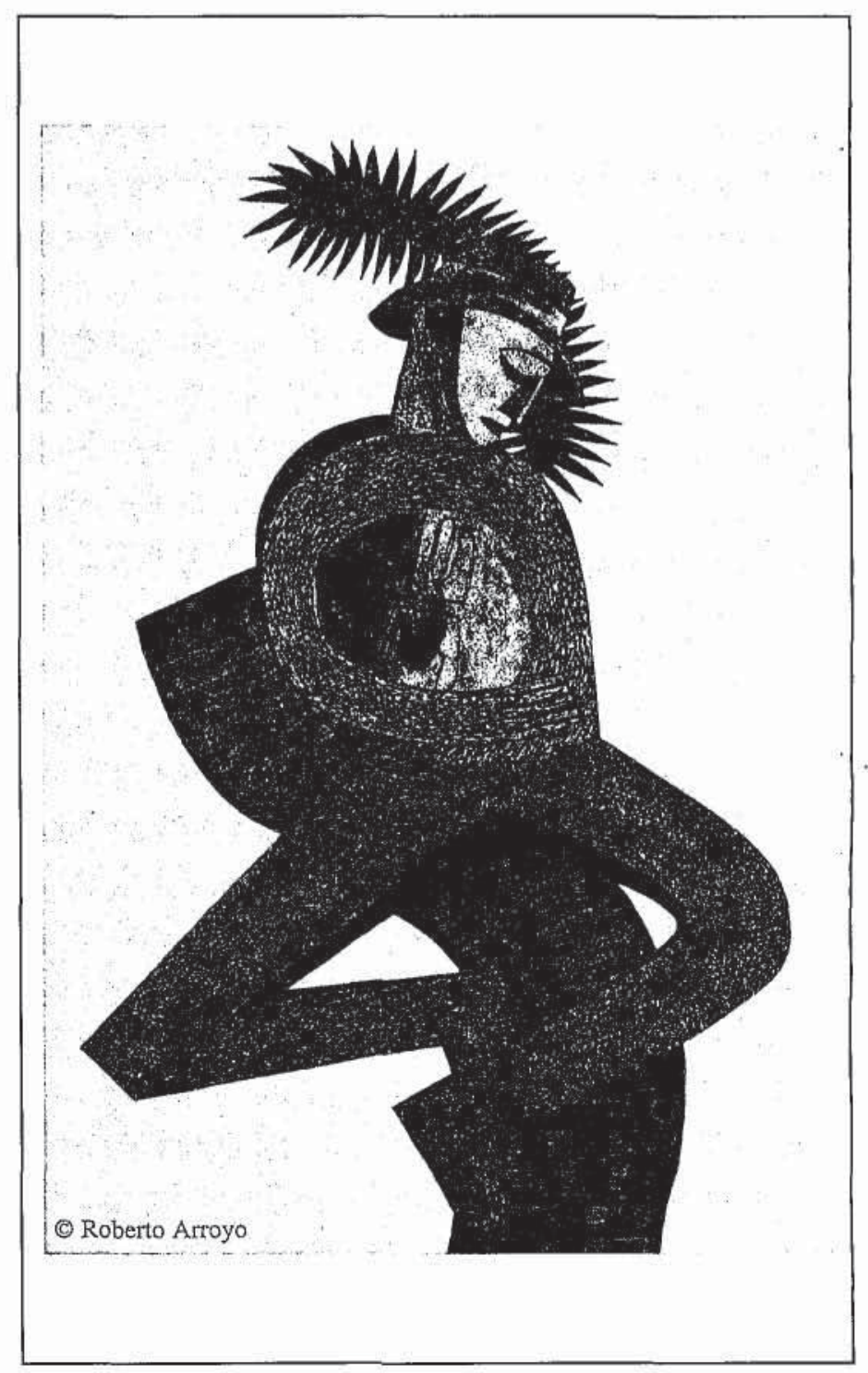




\section{Grabado 2.}

En el centro del hombre se dibuja un ojo que se puede ver mejor si se mira horizontalmente. En la pupila un hombre es ejecutado, en su pecho la sangre fluye. El hombre sostiene con una mano o más bien se afirma a los cachos de un toro, símbolo de fuerza para aguantar el horror. En la mano derecha y pierna izquierda se ven dos ojos, símbolos de los "ojos testigos» de la muerte, de la violencia.

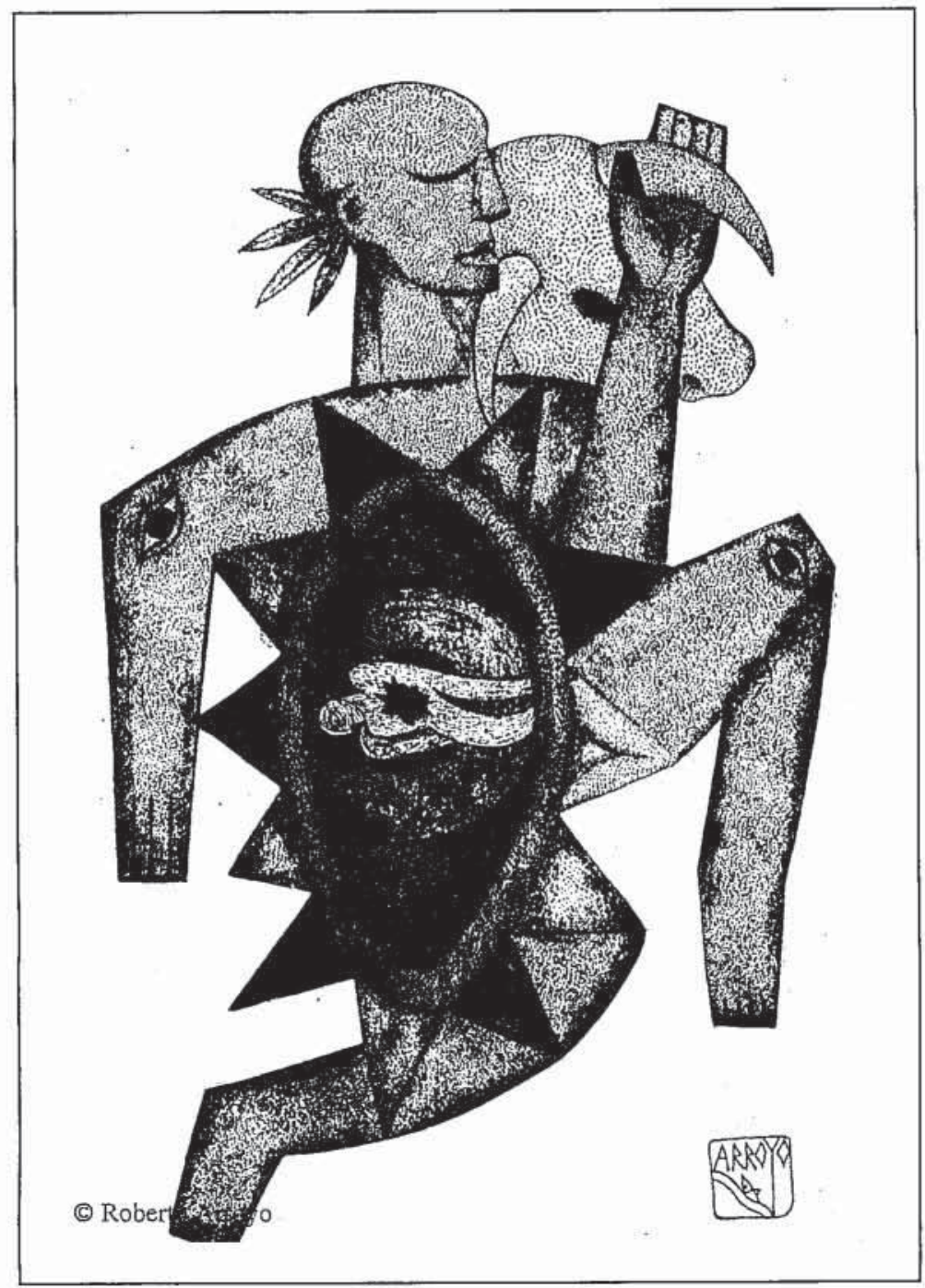

